\title{
Perforator Flaps in Head and Neck Reconstruction
}

\author{
Jagdeep S. Chana, M.D., F.R.C.S.(Plast.), ${ }^{1}$ and Joy Odili, M.D., F.R.C.S.(Plast.) ${ }^{1}$
}

Free tissue transfer has revolutionized the management of complex head and neck defects. Perforator flaps represent the most recent advance in the development of free flap surgery. These flaps are based on perforating vessels and can be harvested without significant damage to associated muscles, thereby reducing the postoperative morbidity associated with muscle-based flaps. Elevation of perforator flaps requires meticulous technique and can be more challenging than raising muscle-based flaps. Use of a Doppler device enables reliable identification of the perforating vessels and aids in the design of freestyle free flaps, where the flaps are designed purely according to the perforator located. The major advantage of free-style free flaps is that an unlimited number of flaps can potentially be designed on much shorter pedicles. The anterolateral thigh flap is the most commonly used perforator flap in head and neck reconstruction. Its use is described in detail, as is use of other less common perforator flaps. This article also describes head and neck reconstruction in a region-specific manner and gives a short-list of suitable flaps based on the location of the defect.

KEYWORDS: Anterolateral thigh flap, head, neck, perforator flaps, scalp

The immediate reconstruction of head and neck defects after surgical resection continues to challenge the reconstructive surgeon, who must achieve a satisfactory functional and aesthetic outcome. Several local flaps, such as the deltopectoral flap and the pectoralis major musculocutaneous flap, were developed for this purpose. ${ }^{1-3}$ Pedicled flaps are easy to harvest but are limited by their pedicles, often require multiple surgical procedures, and do not always contain the necessary tissue components. The advent of free tissue transfer revolutionized the field of head and neck reconstruction. Since the first report by Seidenberg et al in 1959, free flaps have been used to reconstruct single or composite tissue defects in the head and neck, resulting in superior functional and aesthetic results in one-stage procedures. ${ }^{4-6}$
Perforator flaps represent the most recent advance in microvascular surgery. A perforator flap is defined as a flap of skin or subcutaneous tissue based on a "perforating vessel." Using enhanced microsurgery techniques, surgeons are able to dissect the blood vessels through the muscle tissue and take them along with the overlying skin and subcutaneous tissue without sacrificing the underlying muscle. Muscle can be incised to expose the underlying perforators; the muscle can then be repaired, avoiding the problem of muscle weakness or hernias. As muscle pain is one of the most common complaints of patients after flap surgery, postoperative recovery time is reduced as a consequence of less pain. ${ }^{8}$ Reduced morbidity reduces the length of hospital stay and is therefore more cost-effective. Functional muscle is left at the
${ }^{1}$ Department of Plastic and Reconstructive Surgery, Mount Vernon Hospital, Northwood, Middlesex, United Kingdom.

Address for correspondence and reprint requests: Jagdeep $\mathrm{S}$. Chana, M.D., F.R.C.S., Department of Plastic and Reconstructive Surgery, Mount Vernon Hospital, Northwood, Middlesex HA6 2RN, UK (e-mail: jchana@doctors.org.uk).

Advances in Head and Neck Reconstruction, Part II; Guest Editors,
Samir Mardini, M.D., Christopher J. Salgado, M.D., and Hung-Chi Chen, M.D., F.A.C.S.

Semin Plast Surg 2010;24:237-254. Copyright (C) 2010 by Thieme Medical Publishers, Inc., 333 Seventh Avenue, New York, NY 10001, USA. Tel: +1(212) 584-4662.

DOI: http://dx.doi.org/10.1055/s-0030-1263066.

ISSN $1535-2188$ 
donor site, and the transfer of denervated muscle is avoided, allowing increased predictability in the bulk of the flap.

The variable anatomy and the necessity for intramuscular dissection of perforators has in the past given perforator flaps a reputation of requiring a relatively difficult dissection technique. However, in recent years advances in perforator flaps have provided familiarity with the technique required for safe dissection, and in turn this has popularized the use of this type of flap for a wide variety of indications. ${ }^{9-12}$

The classification of perforator flaps is complex, and many classifications have been suggested. A simple strategy involves separating perforator flaps into two groups: those that pass directly through muscle to supply skin or subcutaneous tissues, and those that do not $^{13}$ (Fig. 1). In this second group, the perforators may pass directly through subcutaneous fat or through an intermuscular septum. Both types of perforators can be found supplying the same subcutaneous tissue, allowing versatility in the design and orientation of the flap.

Elevation of perforator flaps requires the careful dissection of, often, small vessels through muscle, which can be challenging. A meticulous technique is required to avoid traumatizing, stretching, or kinking the vessels. The perforators themselves are often variable in size and position, making surgery technically more demanding for the surgeon. Doppler ultrasound is useful for locating perforating vessels preoperatively, with a strong correlation between audible volume signal and perforator diameter. ${ }^{14,15}$

Perforator flaps are particularly attractive in cases where flaps are planned on the basis of the location of a perforating vessel. These so-called free-style perforator flaps are designed at the time the perforator is located either by Doppler ultrasound signal or after an explor-

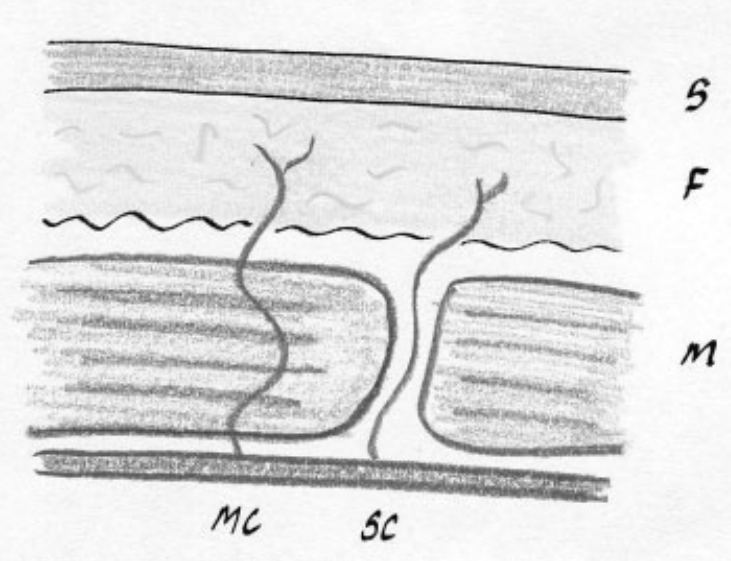

Figure 1 Classification of perforator flaps. MC, musculocutaneous perforator passing through muscle; SC, septocutaneous perforator passing through fat or intermuscular septum; S, skin; F, fat; $M$, muscle. atory incision. ${ }^{16}$ There is thus an unlimited number of potential donor sites, allowing unparalleled versatility in flap design. The perforators may be smaller, with a shorter pedicle.

\section{PERFORATOR FLAPS IN HEAD AND NECK RECONSTRUCTION}

The choice of perforator flaps used in head and neck reconstruction depends upon several factors, including the area and volume of the recipient site. Whichever flap is chosen, the donor site should have four main features:

1. A predictable and consistent blood supply.

2. At least one perforator.

3. Sufficient pedicle length.

4. Minimal functional morbidity with improved cosmetic outcome.

In the past, the radial forearm flap was used in the head and neck for intraoral reconstruction. ${ }^{17}$ It was ideal as a donor as no muscle was sacrificed. The flap is supple with a long, large, consistent and reliable pedicle. It can be raised synchronously during head and neck surgery and can be sensate if required. These factors have all contributed to making this flap popular for soft tissue reconstruction in the head and neck. Unfortunately, there are limitations with the flap ${ }^{18}$ :

- A major limb vessel is sacrificed.

- Where a large flap is required, the donor site needs to be closed with a full- or split-thickness skin graft, which aesthetically is unsightly.

- Tendon exposure is a potential complication.

As an alternative, where larger flaps are required, some surgeons have opted for the free latissimus dorsi musculocutaneous flap. Here a large flap can be harvested leaving a donor site that can be closed directly. Additional flaps such as the scapular and parascapular flaps may be used on the same pedicle. The main limiting factor in head and neck surgery, however, is the need to reposition the patient for flap harvest after tumor resection, thereby prolonging operative times. This contributes to the unsatisfactory result that can be obtained using this flap.

The rectus abdominis has been used for reconstruction of the tongue where volume and height are restored with the bulk of this flap. It has been the most commonly used flap for total glossectomy. However, this flap may result in abdominal wall complications such as weakness and hernia formation. ${ }^{19}$

Perforator flaps fulfill all the criteria of the above three flaps but without donor site morbidity. Perforator flaps used in head and neck reconstruction include (Table 1): 
Table 1 Perforator Flaps Used in Head and Neck Reconstruction

\begin{tabular}{|c|c|c|c|c|}
\hline $\begin{array}{l}\text { Perforator } \\
\text { Flap }\end{array}$ & Study and Year & Indications & Advantages & Disadvantages \\
\hline ALT & Song et al, $1984^{20}$ & $\begin{array}{l}\text { Scalp, intraoral, tongue, } \\
\text { midface, skull base, neck }\end{array}$ & $\begin{array}{l}\text { Large defects; 3D defects; } \\
\text { donor site closed directly; } \\
\text { long pedicle; chimeric design; } \\
\text { sensate }\end{array}$ & May be hairy \\
\hline AMT & Song et al, $1984^{20}$ & $\begin{array}{l}\text { Scalp, intraoral, tongue, } \\
\text { midface, skull base, neck }\end{array}$ & $\begin{array}{l}\text { Thin and pliable; venous } \\
\text { supercharging possible with } \\
\text { saphenous vein; provides } \\
\text { vascularized fascial grafts }\end{array}$ & Variable anatomy \\
\hline DIEP & Koshima and Soeda, $1989^{46}$ & $\begin{array}{l}\text { Scalp, tongue, midface, } \\
\text { skull base }\end{array}$ & Large defects; bulky flap & May require debulking \\
\hline TAP & Angrigiani et al, $1995^{12}$ & $\begin{array}{l}\text { Scalp, midface, } \\
\text { skull base, oral cavity }\end{array}$ & $\begin{array}{l}\text { Thin and pliable; long pedicle; } \\
\text { for shallow defects; } \\
\text { hidden donor site }\end{array}$ & $\begin{array}{l}\text { May require patient } \\
\text { repositioning }\end{array}$ \\
\hline GAP/sGAP & $\begin{array}{l}\text { Koshima et al, } 1993^{11} \\
\text { Allen and Tucker, } 1995^{52}\end{array}$ & Tongue, cheek & $\begin{array}{l}\text { Well-concealed donor site; fatty } \\
\text { flap ideal for contour defects }\end{array}$ & $\begin{array}{l}\text { Short pedicle; may } \\
\text { require patient } \\
\text { repositioning }\end{array}$ \\
\hline PAP & $\begin{array}{l}\text { Yoshimura et al, } 1984^{62} \\
\text { Yang, } 2000^{103}\end{array}$ & $\begin{array}{l}\text { Intraoral, mandible, neck } \\
\text { contractures, maxilla }\end{array}$ & $\begin{array}{l}\text { Thin pliable flap; donor site } \\
\text { closed directly; sensate }\end{array}$ & $\begin{array}{l}\text { Short pedicle; small } \\
\text { defects only }\end{array}$ \\
\hline Submental & Martin et al, $1993^{69}$ & Midface and chin & $\begin{array}{l}\text { Excellent color match; } \\
\text { concealed scars }\end{array}$ & $\begin{array}{l}\text { Short pedicle; hirsute } \\
\text { flap in men }\end{array}$ \\
\hline DCIA & $\begin{array}{r}\text { Kimata et al, } 2001^{76} \\
\text { Safak et al, } 1997^{75}\end{array}$ & Mandible, intraoral & $\begin{array}{l}\text { Can be raised as chimeric flap; } \\
\text { provides bone }\end{array}$ & Small skin paddle \\
\hline
\end{tabular}

ALT, anterior lateral thigh; AMT, anteromedial thigh; DIEP, deep inferior epigastric artery perforator; TAP, thoracodorsal artery perforator; GAP, gluteal artery perforator; sGAP, superior gluteal artery perforator; PAP, peroneal artery perforator; DCIA, deep circumflex iliac artery; 3D, threedimensional.

- Anterolateral thigh (ALT) perforator flap

- Anteromedial thigh (AMT) perforator flap

- Deep inferior epigastric artery perforator (DIEP) flap

- Gluteal artery perforator (GAP) flap

- Thoracodorsal artery perforator (TAP) flap

- Peroneal artery perforator (PAP) flap

- Submental perforator flap

- Deep circumflex iliac artery (DCIA) perforator flap.

\section{THE ANTEROLATERAL THIGH FLAP}

The ALT flap, first described by Song et al in $1984,{ }^{20}$ has become the flap of choice for soft tissue reconstruction of the head and neck. Song et al described a septocutaneous flap based on the descending branch of the lateral circumflex artery. ${ }^{20}$ It was later determined that the flap was supplied only by musculocutaneous perforators in the majority of cases and that septocutaneous supply only occurred in a small percentage of cases. $^{21-24}$

Use of this flap for the reconstruction of head and neck defects was first described more than a decade ago. ${ }^{25-27}$ Further reports have outlined the utility of this flap in head and neck reconstruction as it can be adapted to cover most defects of the face, neck, or intraoral regions. ${ }^{24,28-31}$ The flap can be thinned for pure intraoral defects. It also has good pliability and can be folded for the reconstruction of both the inner and outer lining of through-and-through defects. The vascular pattern also allows use of a more versatile design with double skin paddles based on multiple perforators. In addition, the flap can be used in combination with vastus lateralis muscle as a myocutaneous flap or combined with adjacent flaps according to the chimeric flap principle to reconstruct large or complex three-dimensional defects. The ALT flap can be harvested with fascia lata to provide a vascularized fascial sling when the facial nerve has been damaged or removed. ${ }^{32}$

\section{Flap Anatomy}

The ALT flap is supplied by the descending branch of the lateral circumflex femoral artery (LCFA), which is the largest branch of the profunda femoris system (Fig. 2). The pedicle lies in the groove between the rectus femoris and vastus lateralis muscles along with the motor nerve to the vastus lateralis. The anterior branch of the lateral cutaneous nerve of the thigh can be included to create a sensory flap. The pedicle length ranges between $8 \mathrm{~cm}$ and $16 \mathrm{~cm}$ with a vessel diameter larger than $2 \mathrm{~mm}$. The pedicle supplies perforating branches to the surrounding rectus femoris and vastus lateralis muscles and septocutaneous vessels to the ALT 


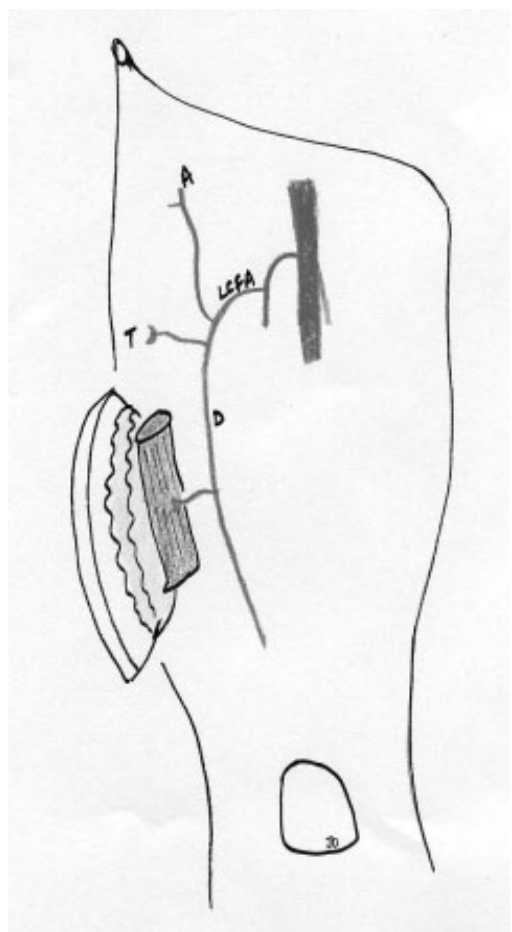

Figure 2 Anatomy of the ALT flap. LCFA, lateral circumflex femoral artery; A, ascending branch; $T$, transverse branch; $D$, descending branch.

skin. In some instances, the predominant vascular supply to the flap may originate from the transverse branch of the LCFA or even directly from the profunda femoris system.

\section{Flap Dissection}

With the patient in a supine position, a line is drawn from the anterosuperior iliac spine to the superolateral border of the patella, indicating the muscular septum between rectus femoris and vastus lateralis muscles. Cutaneous perforators are mapped using a Doppler probe centered over the midpoint of this line. ${ }^{22,24,33}$ The majority of skin perforators are located within a circle of $3-\mathrm{cm}$ radius centered at this midpoint. Xu et al located at least one perforator in the inferolateral quadrant of this circle in $80 \%$ of cases. ${ }^{21}$ The flap is centered over the location of these vessels, and its long axis is designed parallel to that of the thigh (Fig. 3A).

Dissection usually begins at the medial border of the flap over the rectus femoris muscle (Fig. 3B). An incision is made through the deep fascia, and the flap is raised laterally toward the intermuscular septum located between rectus femoris and vastus lateralis. At this stage, the descending branch of the LCFA is identified in the groove between the rectus femoris and vastus lateralis. A septocutaneous vessel may be identified that facilitates further dissection. However, in the largest series to date, septocutaneous vessels were encountered in only $12.9 \%$ of cases. ${ }^{24}$ Therefore, in the majority of cases flap harvest requires a careful dissection of a suitable intramuscular perforator. The course of the perforator can easily be traced by dividing the muscle over the perforator and ligating or cauterizing the small branches to the muscle. The perforator is traced back to the main descending branch of the LCFA, which is divided according to pedicle length requirements (Fig. $3 \mathrm{C}-\mathrm{H}$ ).

In the majority of cases, the flap is harvested as a fasciocutaneous flap. When a thin pliable flap is required for intraoral defects, a cutaneous flap may be raised using a suprafascial dissection (Fig. 4A). Once a suitable skin perforator is identified, the flap is raised suprafascially, and a small cuff of fascia is maintained around the perforator (Fig. 4B). The cutaneous flap can be further thinned to $5 \mathrm{~mm}$, but excessive thinning should be avoided to prevent marginal necrosis. Indications for thin ALT flaps include reconstruction for hemi-tongue, buccal mucosa, palate and pharyngeal wall, and scalp.

When soft tissue bulk is required for the reconstruction, the flap may be raised as a musculocutaneous flap. The skin and muscle components can be raised on different branches of the same vascular pedicle as a bipaddled composite flap (Fig. 5). In the majority of cases, an intramuscular dissection of the perforator is not required. However, it is prudent to determine the course of the perforator to the source vessel by de-roofing the muscle fibers over the chosen perforator as the perforator may have a variable and tortuous intramuscular course. This maneuver avoids inadvertent injury to the perforator during incision of the muscle and also establishes that the perforator supplies the skin paddle of the musculocutaneous flap. Determining the course of the perforator to the source vessel is important because in $10 \%$ of cases, the perforator may arise from the transverse branch of the lateral circumflex artery, entering the muscle superiorly with a vertical course, and is liable to damage during muscle incision at the upper border of the flap. ${ }^{28}$

\section{Advantages in Head and Neck Reconstruction}

Large defects of the head and neck are challenging to reconstruct as there may be a three-dimensional requirement of both volume and multiple surfaces of oral lining and external skin. In these situations, the chimeric ALT flap is particularly versatile. As the LCFA gives off lateral, medial, and descending branches, multiple components can be harvested based on the main pedicle. There are many combinations of chimeric ALT flaps, the majority of which are combined with the rectus femoris muscle, tensor fascia lata, anteromedial thigh skin, and vastus lateralis muscle. ${ }^{34,35}$ Double skin paddle flaps may also be used with each paddle based on separate perforators. ${ }^{32}$ Musculocutaneous flaps can also be raised with muscle and skin paddles based on separate perforators. 
A
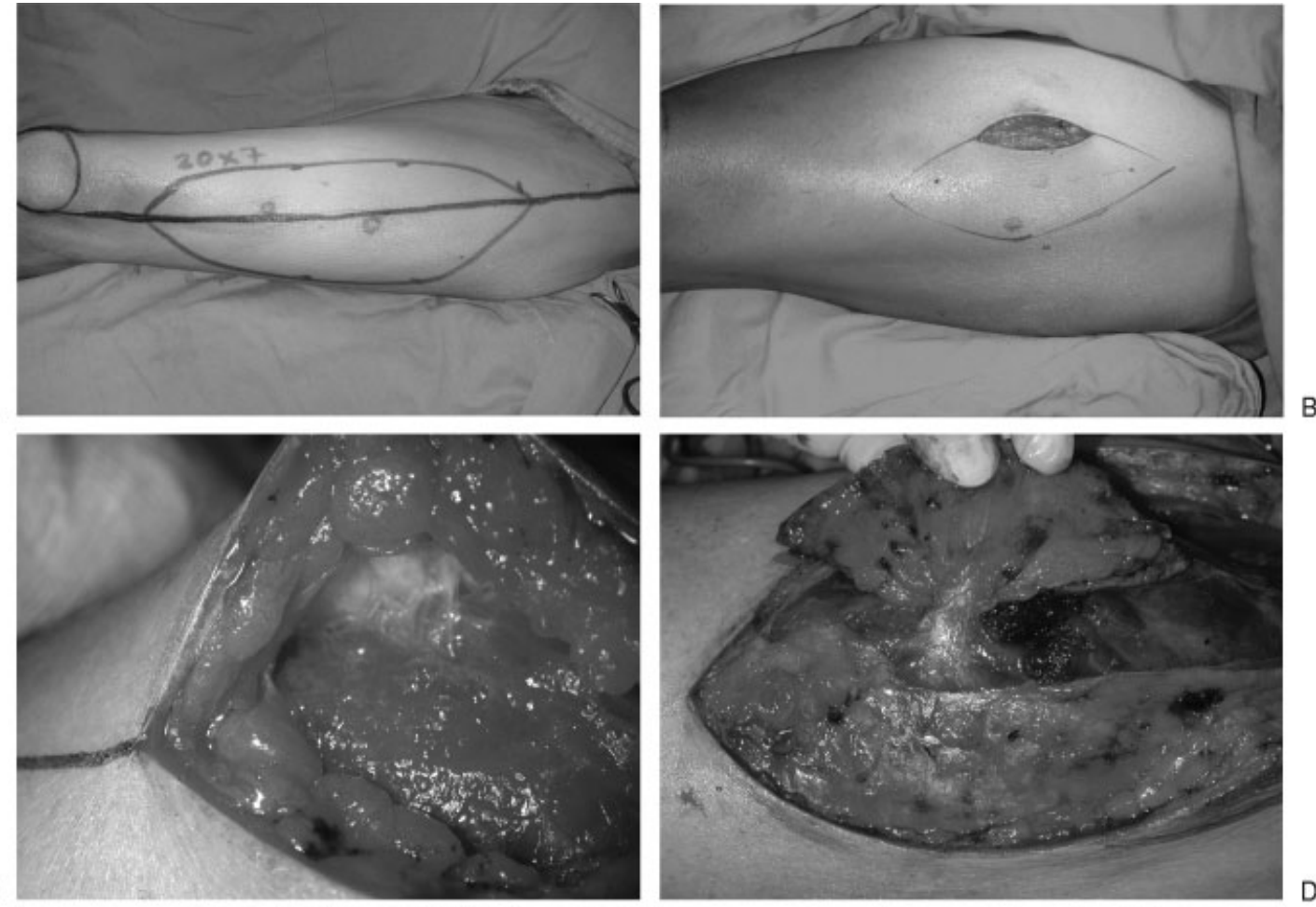

$B$

C
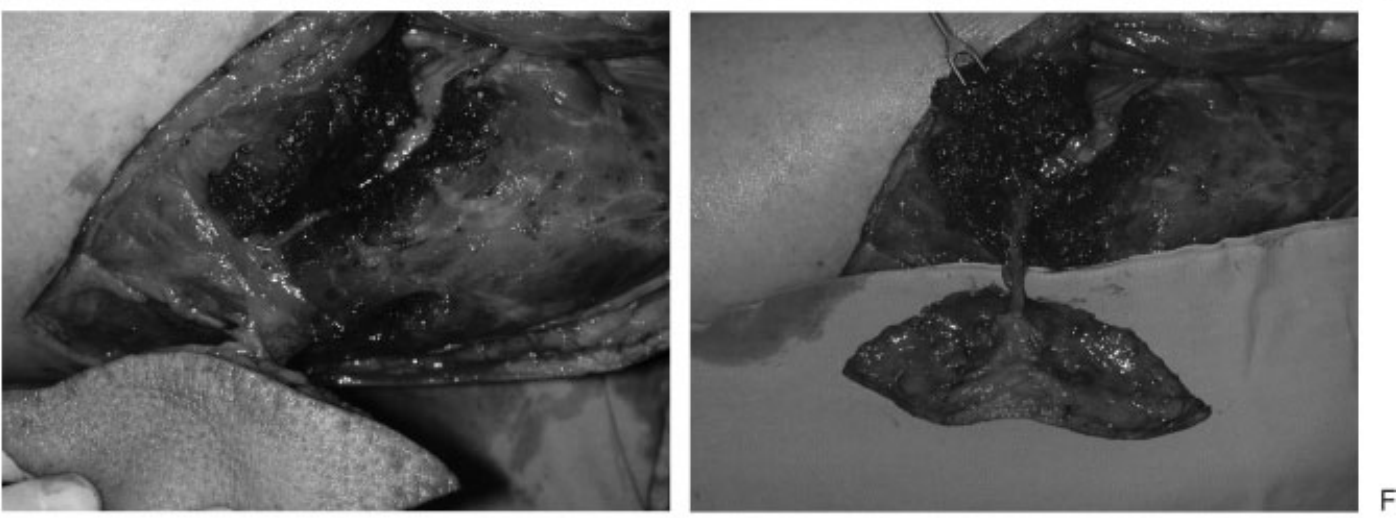

$\mathrm{E}$
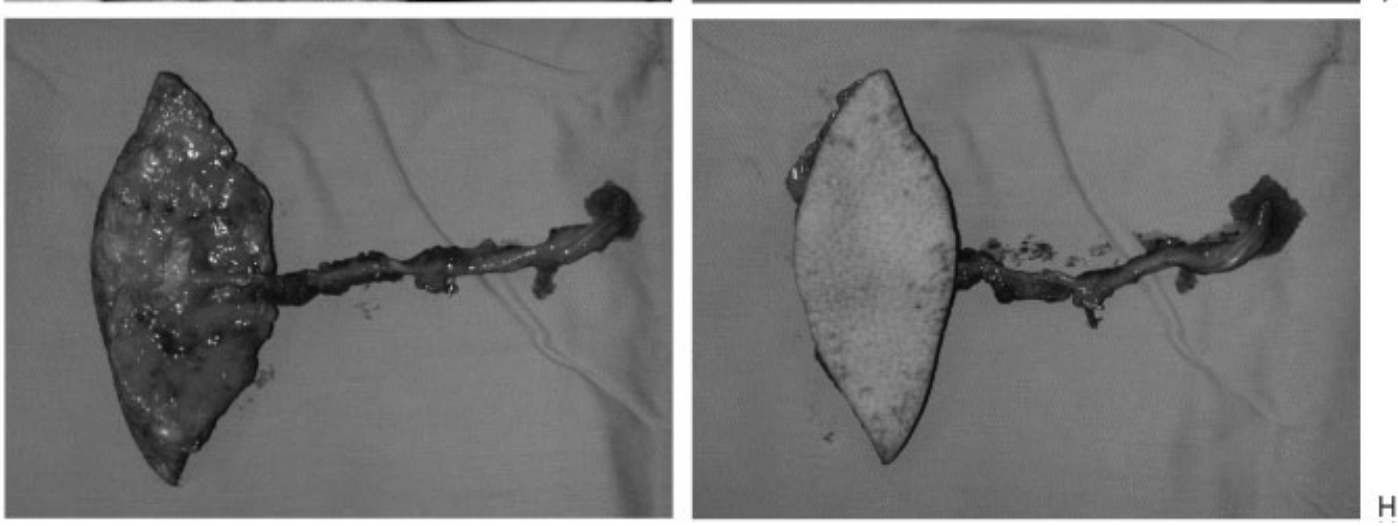

Figure 3 ALT flap dissection. (A) Flap design. (B) Dissection at medial border of flap. (C) Musculocutaneous perforator. (D, E) Intramuscular dissection. (F) Flap pedicle. (G, H) Views of skin paddle.

This versatility facilitates insetting of the flap to complex three-dimensional defects (Fig. 6).

When there is no available second recipient vessel and a double free flap is required, the ALT flap can be used in a piggy-back arrangement with a second flap.
During flap dissection, the pedicle of the flap is dissected distally into the vastus lateralis to the required length, and this distal end can then be used for anastomosis of a second free flap. This arrangement thereby allows perfusion of two free flaps connected in series. 
A
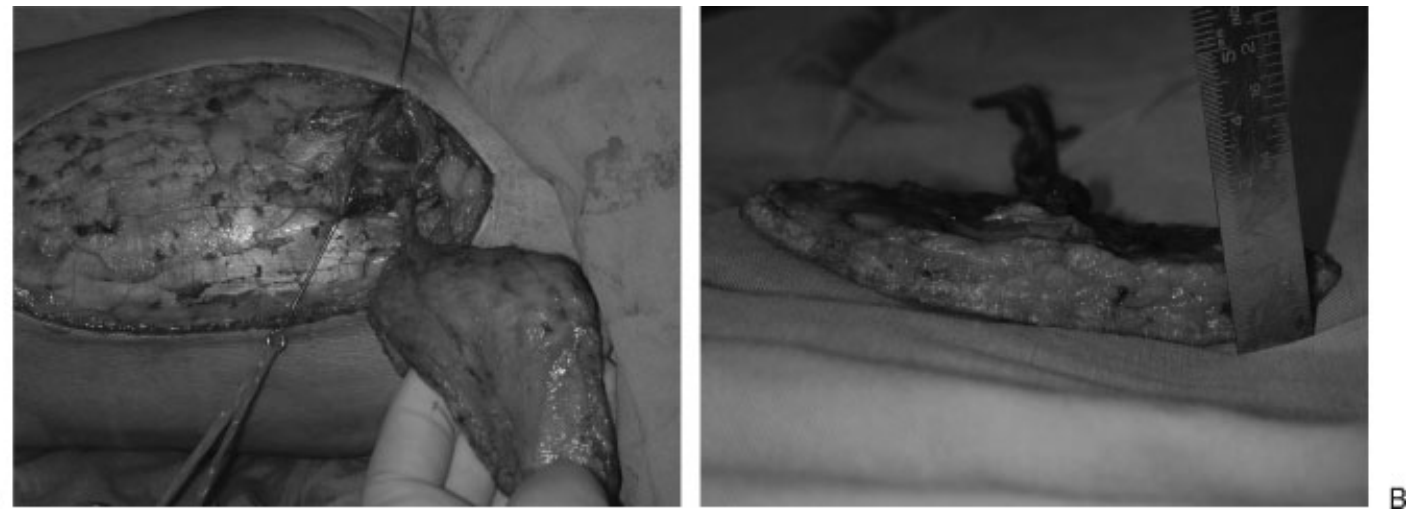

Figure 4 (A) Suprafascial ALT flap dissection. (B) Pedicle with small cuff of fascia.

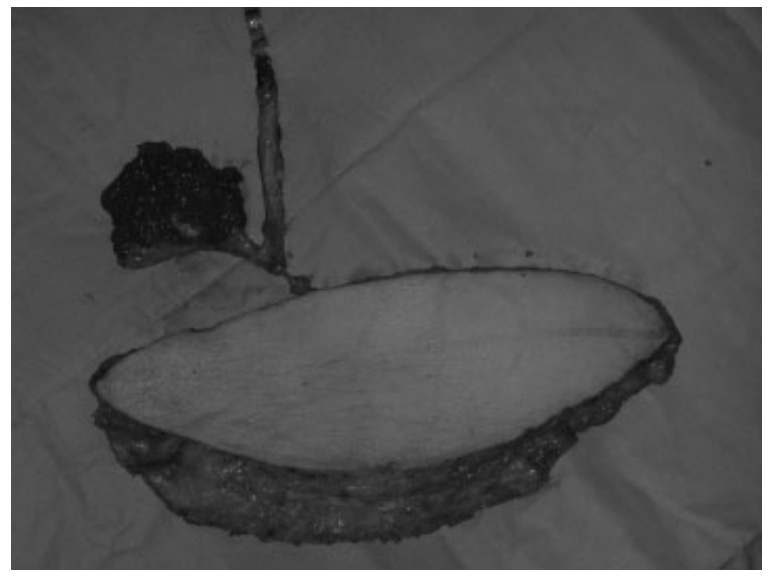

Figure 5 Bi-paddled composite flap.

A
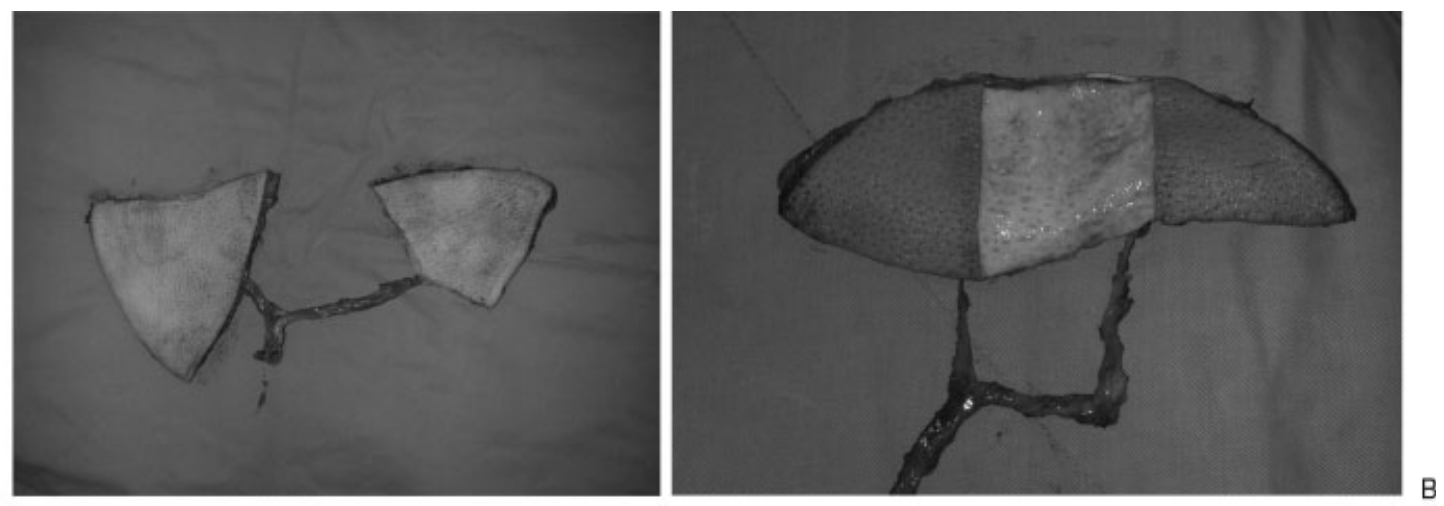

C

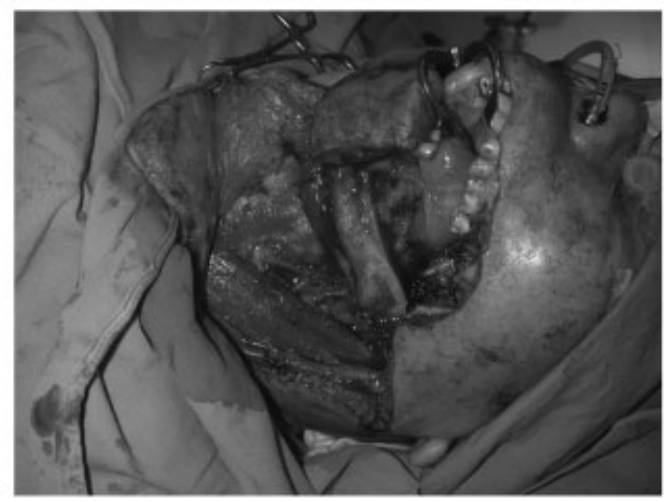

Figure 6 (A) Two skin paddles served by different perforators. (B) Central portion of bi-paddled ALT de-epithelialized for bulk. (C) Midface defect requiring oral lining and skin cover. 


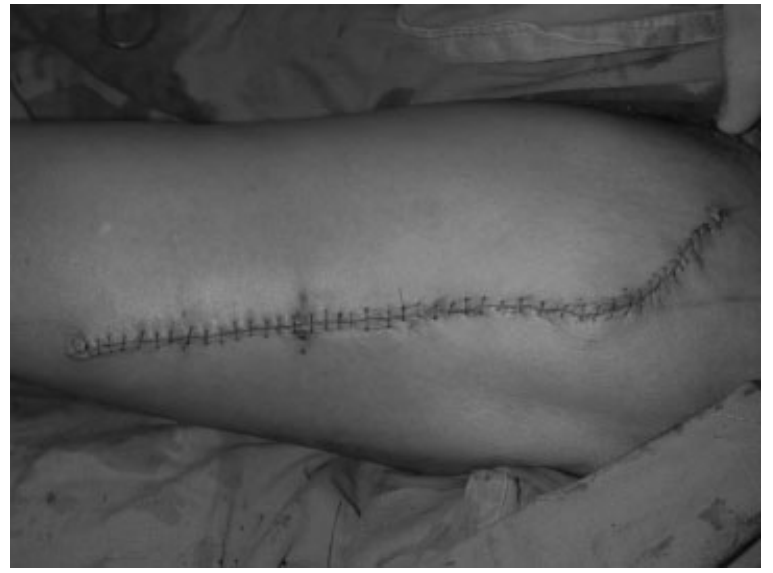

Figure 7 ALT flap donor site.

\section{Donor Site Morbidity}

One of the primary advantages of the ALT flap is the reduced donor site morbidity (Fig. 7). Few other donor sites in the body offer such an ample amount of sensate skin and muscle for the reconstruction of through-andthrough tumor defects in the head and neck. To preserve maximal quadriceps function, a careful dissection and preservation of the nerve to the vastus lateralis should be performed. Kimata et al observed that weakness of the limb was related to the degree of muscle dissection and if a skin graft had been used. ${ }^{36}$ Use of a V-Y perforatorbased local advancement flap has been described to avoid use of a skin graft. Other authors have not found the donor site to be problematic. Even when the vastus lateralis was transferred as a free muscle flap, Wolff and Grundmann found that there was no motor dysfunction in their series, confirmed by clinical comparison of the load capacity of both legs. ${ }^{33}$ In a further report, Kuo et al showed objectively, using a kinetic communicator machine, that patients who underwent a myocutaneous ALT flap showed minimal weakness of the donor thigh at long-term follow-up. ${ }^{37}$

\section{OTHER COMIMON PERFORATOR FLAPS}

\section{Anteromedial Thigh Perforator Flap}

Originally described by Song et al, the AMT perforator flap is based on the septocutaneous perforator from the medial branch of the lateral circumflex femoral vessels and the long saphenous vein. ${ }^{20,38}$ The vascular pedicle is thought to emerge at the intersection of the medial border of the rectus femoris muscle with the sartorius muscle. ${ }^{39}$ A pedicle length of up to $12 \mathrm{~cm}$ can be obtained. The anterior cutaneous branch of the femoral nerve provides sensory innervation. The lateral border of the flap is formed by a line from the anterior superior iliac spine to the middle of the patella. When raising the AMT flap, the first incision is placed in this line and the flap raised medially until the main perforating vessels are located. The pedicle is then dissected down to its origin from the descending branch of the LCFA.

The AMT perforator flap has been used mainly for lower-limb defects as well as in the head and neck region. ${ }^{23,35,38,40,41}$ It is a useful skin flap and can be modified for use as vascularized fascia graft or fasciocutaneous free flap. ${ }^{42}$ It can be de-epithelialized and used for contour correction and filling dead space. ${ }^{41}$ Koshima et al have used the AMT perforator flap for intraoral reconstruction. ${ }^{35,40,43}$ The saphenous vein can be included in the flap for venous charging. The dissection of the pedicle can be technically challenging but, in the event of problems with the vessels, the ALT perforator flap or the gracilis muscle flap can be harvested as alternatives through the same incision.

\section{Deep Inferior Epigastric Artery Perforator Flap}

The DIEP flap based on the deep inferior epigastric vessels is a large flap commonly used in breast reconstruction. ${ }^{10,44,45}$ Originally described by Koshima and Soeda, ${ }^{46}$ it evolved as a modification of the transverse rectus abdominis muscle flap, providing a large amount of skin and subcutaneous tissue without the donor site morbidity. ${ }^{8,47}$ It has also been used more recently in head and neck reconstruction after cancer resection ${ }^{48}$ and is particularly useful where soft tissue bulk is essential. It can be used to reconstruct tongue, floor of mouth, and cheek defects after parotidectomy and mastoidectomy. Koshima et al have used this flap to reconstruct the cheek regions after the resection of large arteriovenous malformations after selective embolization. ${ }^{49}$ In this case, motor nerve from the rectus muscle was also harvested and coapted to the buccal branch of the facial nerve to provide movement of the upper lip. The perforator flap is used not only to reconstruct a complex surgical defect but also to improve the local hemodynamics of the surgical bed, thereby preventing recurrence of the vascular malformation. It has the added advantage of being raised at the same time as tumor resection without the need for patient repositioning. The DIEP flap has the potential for dynamic reconstruction of facial reanimation. ${ }^{49}$

\section{Gluteal Artery Perforator Flap}

Gluteal soft tissue was first used to reconstruct the breast as early as $1975 .{ }^{50}$ There were several drawbacks to using this flap. Flap dissection is difficult, and exposure of the donor vessels risks injury to the adjacent sciatic nerve. Partial resection of the gluteus maximus muscle resulted in weakness of thigh abduction and extension. Recently, the GAP flap, originating from the gluteal artery, has been used to repair sacral pressure sores. ${ }^{11,51}$ The free superior gluteal artery perforator (sGAP) flap has been used widely for breast reconstruction. ${ }^{52,53}$ The sGAP 
flap has also been used for augmentation of depressed deformities of the face. ${ }^{49}$ The fatty nature of the flap makes it ideal for filling contour deformities. This flap can be raised without repositioning of the patient when the defect is in the face.

The donor site can be closed directly and is easily concealed by underwear. The pedicle, however, is short and of small caliber. Harvesting of this flap for breast reconstruction usually involves dissection deep into the gluteal muscle to obtain a large enough pedicle to anastomose to large recipient vessels such as the internal mammary vessels. For reconstruction in the head and neck, a short pedicle is a disadvantage. However, a shorter pedicle is useful when anastomosing to the lingual and facial arteries, thereby reducing the operative time significantly.

\section{Thoracodorsal Artery Perforator Flap}

The TAP flap was initially described in $1995^{12}$ and is based on one or more perforators from the thoracodorsal artery. ${ }^{54,55}$ Compared with the DIEP and sGAP flaps, the TAP flap is thin and pliable, making it useful for resurfacing shallower defects and filling contour deformities. ${ }^{55}$ Flap thinning or debulking is rarely indicated. The flap has also been used for skull base reconstruction as well as resurfacing the face and oral cavity. ${ }^{56,57}$ It has a lengthy pedicle making it ideal for head and neck reconstruction; any vessel in the neck can be used without the need for vein grafts. A frequent complication of the latissimus dorsi free muscle flap is seroma formation. This is avoided with the TAP flap. ${ }^{58,59}$ The flap is large with reliable perforators. It can be raised as an extension of the subscapular territory to create a variety of composite flaps that include bone and muscle. ${ }^{60}$ It can also be raised in combination with the latissimus dorsi muscle flap as a chimeric flap for reconstructing complex defects. ${ }^{61}$ The need to reposition patients during surgery makes this flap a secondary or tertiary reconstructive option. Also, because muscle is spared, there is more tension on the skin during closure, which can result in delayed healing and stretched scars. However, the donor site remains well hidden.

\section{Peroneal Artery Perforator Flaps}

Lower-leg flaps based on perforators from the peroneal artery (PAP flaps) have been used mainly for defect coverage in the extremities. ${ }^{62}$ These flaps are useful as pedicled or free flaps and have various applications as osteocutaneous flaps with the fibula, or as musculocutaneous flaps with soleus and peroneus muscles. The sural nerve can also be included to innervate the flap. The method of elevation is relatively simple but ultimately involves sacrificing the peroneal artery, one of the main arteries of the lower leg.
More recently, perforator flaps based on the peroneal artery have been used to reconstruct an extended anterior cervical scar contracture ${ }^{63}$ and to cover small intraoral defects. ${ }^{64}$ This flap is supplied by septocutaneous or myocutaneous perforators and has a small vessel diameter of 1 to $2 \mathrm{~mm}$ and limited pedicle length of 4 to $6 \mathrm{~cm}$. However, the flap is thin and pliable making it extremely useful for covering superficial skin defects and for intraoral reconstruction. Because the flap is thin, the risks of damaging the perforator or reducing the blood circulation during radical thinning of flaps is overcome. The anatomic features of this flap are well known from previous studies. ${ }^{65-68}$ The donor site can be closed directly. The flap is limited to use in patients with minimal hair growth at the donor site. The lateral sural nerve can be included to create a sensate flap.

The pedicle of this flap can be anastomosed to the lingual or facial arteries and concomitant veins lying close to the defects. This maneuver overcomes the potential problem of a short pedicle. Alternatively, the superior thyroid artery can be used. A branch of the perforator has been observed close to the fibula, supplying the peroneal muscles. The osteomyocutaneous PAP flap represents a further refinement of the fibula flap and increases its versatility, with multiple skin paddles, bone segments, and soleus muscle independently isolated. This flap therefore provides a good reconstructive option for composite maxillary or mandibular defects (Fig. 8).

\section{Submental Perforator Flaps}

The submental island flap is based on the submental artery $^{69}$ and is an ideal color and texture match for skin of the lower face and midface. It has the advantage of a well-concealed donor scar. ${ }^{70,71}$ Reversed submental perforator-based flaps have been designed to cover defects around the mouth and nose. ${ }^{69,72}$ In these cases, a separate venous anastomosis is sometimes recommended to prevent flap congestion as the tiny submental vein provides insufficient venous drainage. Alternatively, inclusion of the superficial vein that drains into the common facial vein precludes the need for an additional anastomosis. ${ }^{72}$ The submental area is hairy in men, making it an ideal choice for upper lip reconstruction. The submental perforator flap has the disadvantage of a short pedicle. However, elevating the flap can also provide an opportunity for the surgeon to examine submental and submandibular lymph nodes during reconstruction for cancer.

\section{Deep Circumflex Iliac Artery Perforator Flap}

The DCIA perforator flap has been used to supply musculocutaneous flaps for lower-limb and breast reconstruction. ${ }^{73,74}$ It can also be harvested with bone (iliac crest). The iliac crest is an important donor site 
A
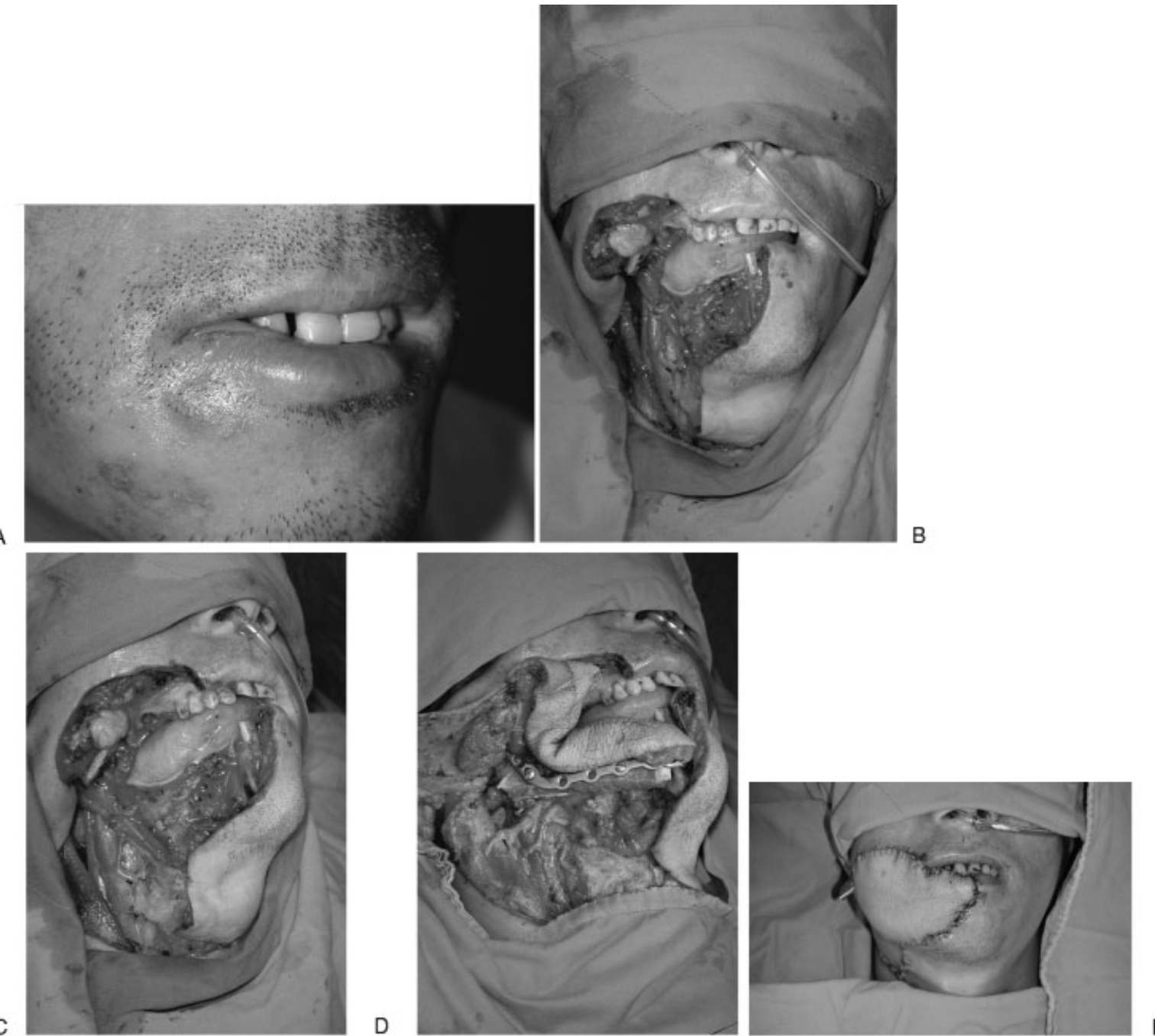

Figure 8 (A) Intraoral tumor. (B, C) Defect after surgical resection. (D) Mandible reconstructed with free peroneal artery perforator flap with fibula. (E) The external skin defect is resurfaced with a free ALT flap.

for reconstructing the mandible after resection. The iliac crest osteocutaneous free flap includes abdominal muscles, making the flap too bulky and immobile for intraoral reconstruction. ${ }^{73}$ The omission of muscle by Safak et al reduced the volume of the flap making it more attractive for intraoral use. ${ }^{75} \mathrm{It}$ has since been proved to be a reliable option for mandibular reconstruction ${ }^{76,77}$ and is more pliable for easier contouring to complex oral cavity defects.

\section{REGION-SPECIFIC RECONSTRUCTION}

\section{Tongue Reconstruction}

The function of the tongue is generally maintained after partial glossectomy. However, after total or neartotal glossectomy, speech and swallowing are disappointing. Larger subtotal defects of the tongue are generally reconstructed with a thin flap such as the radial forearm flap. ${ }^{78,79}$ Recently, the ALT flap has largely replaced the radial forearm flap in reconstruction of tongue defects in some centers. ${ }^{24}$ This flap is pliable, adapts well to three-dimensional defects in the oral cavity, ${ }^{31}$ and the donor site is superior to that of the radial forearm flap as primary closure is achieved. Hemi-tongue defects are reconstructed using a suprafascial dissection to provide a thin sensate ALT flap incorporating the lateral cutaneous nerve of the thigh (Fig. 9A). Partial tongue defects involving more of the floor of the mouth can be reconstructed with a larger flap, part of which may be de-epithelialized and used to fill the dead space and augment the defect in the submandibular region. The AMT and sGAP flaps can also be used as alternative perforator flaps for small tongue defects requiring reconstruction. The relatively easy access to recipient vessels around the tongue allows for use of flaps with shorter pedicles.

Total glossectomy defects require significant bulk to restore height and volume to the reconstructed tongue, and a myocutaneous flap is therefore required. 
A
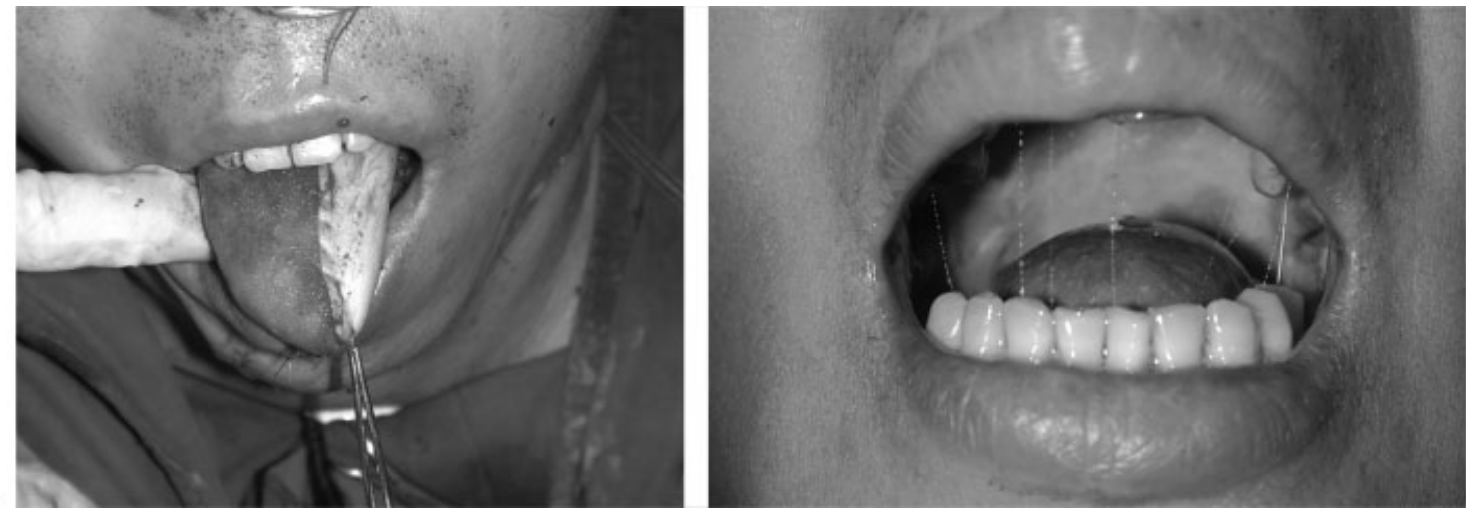

B

Figure 9 Tongue reconstruction with ALT flap. (A) Hemi-tongue reconstruction. (B) Total tongue reconstruction.

Varying amounts of muscle can be included in the ALT flap to fill dead space in the neck from an associated neck dissection. The ALT myocutaneous flap can provide as much volume as a rectus abdominis myocutaneous flap, which previously was the most commonly used flap for total glossectomy reconstruction and has the added advantage of avoiding abdominal wall complications ${ }^{80}$ (Fig. 9B). The other disadvantage of muscle flaps is that the initial bulk usually diminishes with time due to muscle atrophy, especially after radiotherapy. Alternatively, the DIEP flap can be used instead of the rectus abdominis flap, providing similar tissue without donor site morbidity.

A
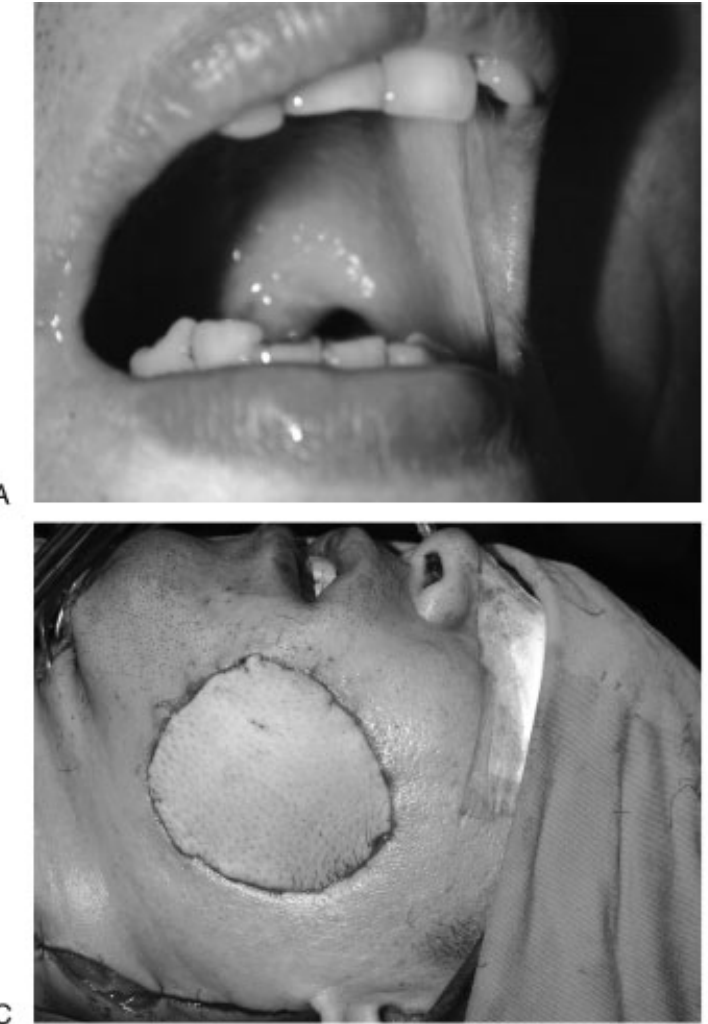

\section{Reconstruction of Intraoral Lining and Buccal Defects}

The radial forearm flap has been the flap of choice for intraoral lining, but perforator flaps are now a useful alternative. Defects requiring reconstruction of oral lining alone are relatively straightforward for which thin ALT flaps may be used (Fig. 10A). The PAP flap is also potentially an ideal substitute as this flap is thin, pliable, and relatively easy to anastomose to vessels close to the mouth. Larger defects in the buccal region may involve external cheek skin resulting in throughand-through defects (Fig. 10B). In this situation, a folded ALT flap can be used with the intervening

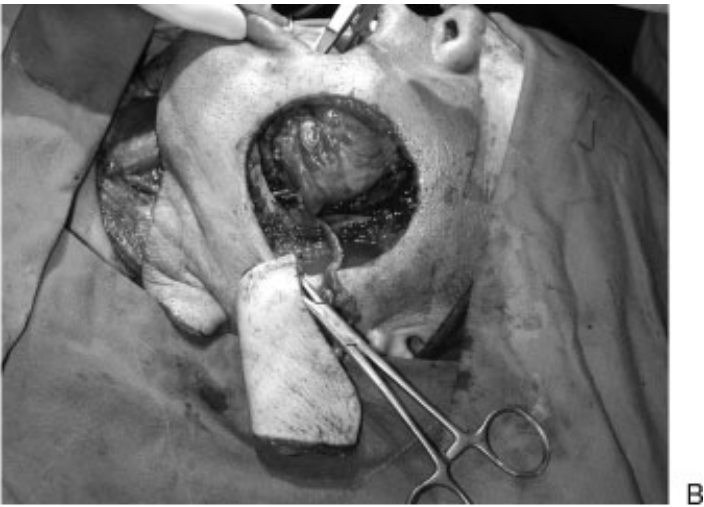

B

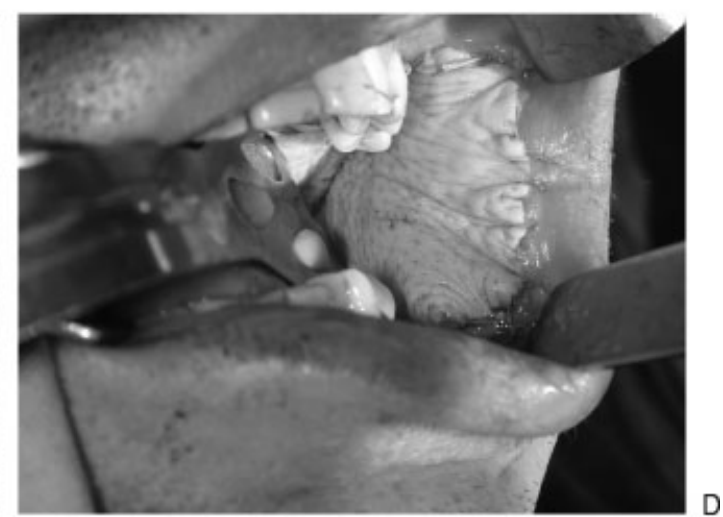

Figure 10 Cheek reconstruction. (A) ALT flap reconstruction of buccal lining. (B-D) Through-and-through cheek defect reconstructed with ALT flap. 
A
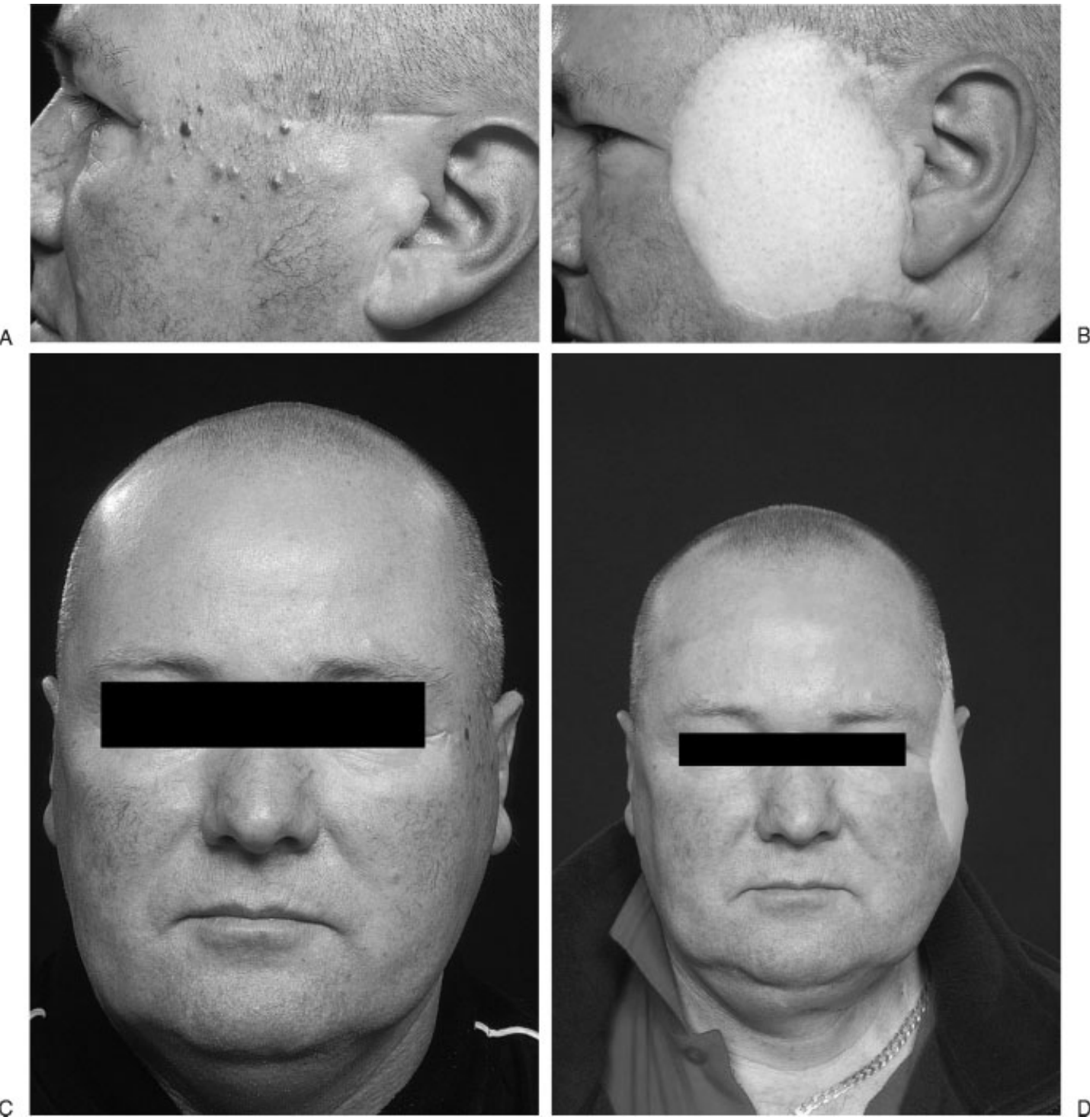

Figure 11 ALT for temple defect. (A) Preoperative lateral view. (B) Postoperative lateral view. (C) Preoperative anteroposterior view. (D) Postoperative anteroposterior view.

folded portion being de-epithelialized (Fig. 6B). These defects have a significant volume deficit, which often results in a long-term sunken appearance of the cheek. In our experience, this can be improved by incorporating muscle with the ALT skin to provide extra bulk that augments the cheek and improves cosmesis (Fig. 10C, D). If two suitable perforators are present, the skin paddle can be split as a chimeric flap, allowing for a more elegant reconstruction. ${ }^{32}$ If the oral commissure is involved in the defect, the fascia lata can be split and sutured into the upper and lower orbicularis oris muscle as a static sling. ${ }^{32}$

\section{External Skin Defects}

The latissimus dorsi myocutaneous flap is the most commonly used flap for reconstructing the scalp. ${ }^{81} \mathrm{It}$ matches the scalp in thickness and is large enough to resurface most of the scalp. The donor site is acceptable where a small flap is needed. However, harvesting a large flap necessitates the grafting of the donor site, which is unsightly. Alternatively, for large scalp defects, a latissimus dorsi muscle-only flap is used with an overlying skin graft, leaving an unsightly scalp flap. The TAP flap could be substituted for this flap to provide an excellent skin match for small defects. However, large TAP flaps may still require skin grafting.

The rectus abdominis flap is another alternative commonly used for midsize scalp and calvarial defects. ${ }^{82}$ This flap tends to be thicker than the scalp defect, although this is said to improve with denervation atrophy. ${ }^{83}$ The problems with excessive flap bulk and donor site problems could be avoided by using a DIEP flap. 
A
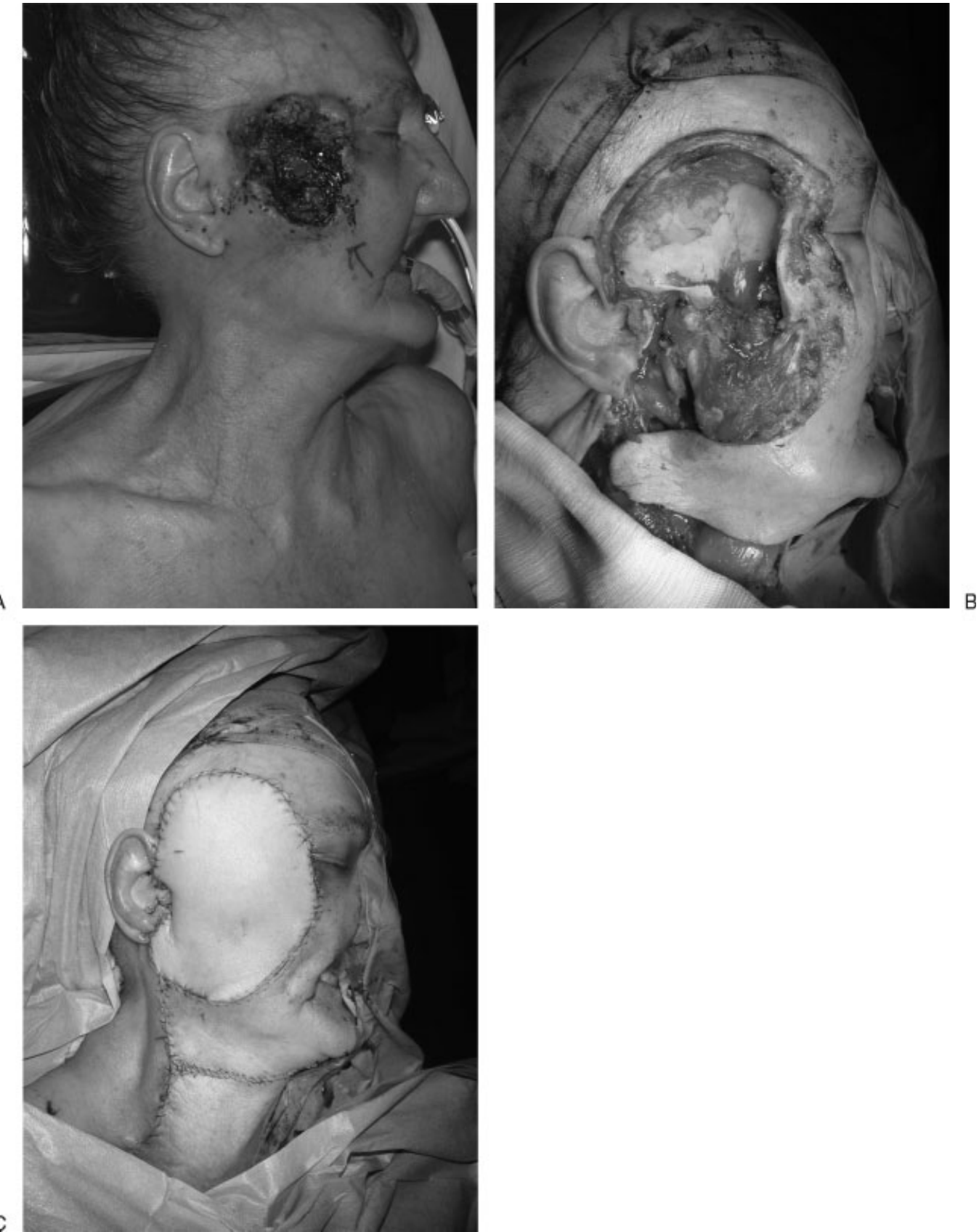

Figure 12 ALT reconstruction of extensive temple and cheek defect. (A) Preoperative lateral view. (B) Defect. (C) ALT flap.

The ALT flap provides an extremely large surface area of $\operatorname{skin}^{29}$ and lends itself to resurfacing extensive external skin defects in the head and neck region (Fig. 11 and Fig. 12). It is particularly useful for resurfacing large scalp defects with bone exposure. ${ }^{84}$ An excellent contour of the scalp is achieved (Fig. 13) without the excessive bulkiness that can result from use of other flaps with a wide skin territory such as the rectus abdominis and latissimus dorsi flaps. It has also been used for reconstruction of severe post-burn anterior cervical neck contractures after failure of other surgical modalities. ${ }^{85} \mathrm{In}$ this situation, free thin ALT flaps provide pliable tissue of large surface area that contour well to the cervicomental angle when combined with a cervicoplasty. ${ }^{85}$ This flap therefore offers potential for the correction of a severe functional disability from neck contractures with a low recurrence rate and an excellent aesthetic outcome.

\section{Extensive Composite Defects of the Mandible}

More extensive composite defects involving segmental resection of the mandible often result in extensive soft tissue loss of the cheek. The skin islands of the osteoseptocutaneous flap may be adequate for coverage of both 
A
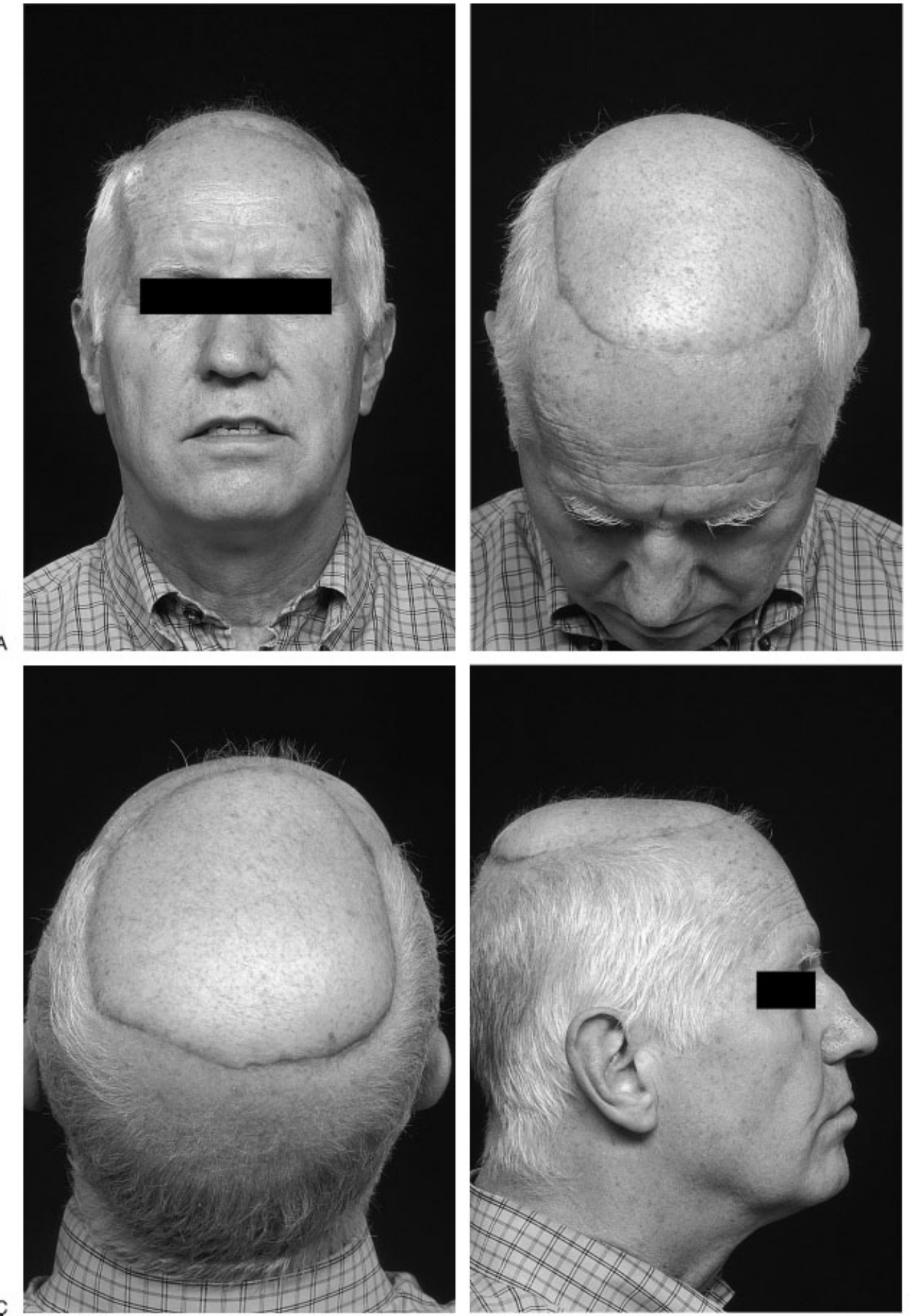

B D

Figure 13 (A-D) Scalp defect reconstructed with ALT flap.

inner and outer lining but inadequate to replace soft tissue loss. Soft tissue reconstruction in these situations has at least as great a significance for the functional result as does the bony reconstruction. ${ }^{86,87}$ The dead space left by extirpation of the masseter muscles, buccal fat, and the parotid gland must be obliterated to prevent fluid accumulation and secondary infection and to prevent further soft tissue contraction. A two-flap procedure in these situations provides adequate volume to prevent these complications and also avoids a sunken appearance of the cheek, which may occur after radiotherapy ${ }^{87}$ (Fig. 8). In edentulous patients or for massive mandibular resections, a free osteoseptocutaneous fibula flap may be used for mandibular reconstruction and inner lining together with a free radial forearm flap or rectus abdominis flap for the cheek. ${ }^{88}$ Alternatively, the iliac crest has 
been used as the flap of choice in dentate patients. These combined vascularized bone grafts and cutaneous flaps with "chain-link" vascular anastomoses are ideal for massive defects in the head and neck. ${ }^{89}$ The radial forearm flap, however, is usually too thin to cover the fibula and reconstruct the palate and has an inferior donor site compared with that of an ALT flap. The rectus abdominis flap may be too bulky and has disadvantages with regard to the abdominal donor site. Also, flap elevation may be prolonged because the donor sites are not in the same area.

The ALT flap combined with a DCIA flap is more suitable in these situations. ${ }^{25,38,87}$ It has a large cutaneous area, ${ }^{29}$ and the volume is easily adjustable by incorporating part of the vastus lateralis muscle. ${ }^{87}$ The vascular pedicle to the bone graft can be separated from that of the skin allowing easier insetting of both flaps into the defect. Various tissues such as rectus femoris and sartorius muscles and fascia lata can also be included in the flap.

Alternatively, chimeric flaps consisting of multiple different flaps or tissues can be used in the head and neck. These flaps are supplied by their own independent pedicles from the same source. An example of this is the rectus femoris muscle and overlying ALT, supplied by different branches from the same source vessel. ${ }^{90} \mathrm{Sim}-$ ilarly, the AMT flap and anterolateral femoral flap are both based on septocutaneous perforators from the lateral circumflex femoral system ${ }^{21}$ and can be combined with a DCIA flap to reconstruct massive composite defects.

\section{Midface Reconstruction}

These defects are complex because they generally involve more than one midfacial component and often require skin cover, mucosal lining, and bony support. Although various free flaps have been used for midface reconstruction, the commonly used flaps include the radial forearm flap for small defects and the rectus abdominis or latissimus dorsi myocutaneous flaps for larger defects combined with bone grafts for orbital support if indicated. ${ }^{91,92}$ Small defects involving palate alone or midfacial skin alone can be reconstructed with a cutaneous or fasciocutaneous ALT flap. Larger defects after maxillectomy require muscle to obliterate the dead space; a DCIA flap with internal oblique is commonly used. A myocutaneous ALT flap provides sufficient volume ${ }^{93}$ in these cases.

An important consideration in midface reconstruction using free tissue transfer is use of recipient vessels. The pedicle has to be long enough to reach donor vessels in the neck. The ALT flap is ideal under these circumstances as a $10-$ to $15-\mathrm{cm}$ pedicle is easily provided. ${ }^{93}$ Flaps harvested according to volume requirement from this single donor site can therefore replace the radial forearm, rectus abdominis, or latissimus dorsi flaps, which have been commonly used for midface reconstruction.

\section{Skull Base Reconstruction}

Skull base surgery is complicated and multifaceted, often resulting in facial disfigurement, functional impairment, and cranial nerve destruction. ${ }^{94}$ Resection of tumors around the anterior and middle skull often involve the removal of bone and dura. This can result in leakage of cerebrospinal fluid and exposure of intradural contents to infections from the surrounding sinuses. ${ }^{95,96}$ Vascularized tissue is used to provide tissue for dural seal. ${ }^{97}$ The resulting defects are often beyond the capacity of local flaps, making free flaps the ideal choice for skull base reconstruction.

Historically, the rectus abdominis muscle or musculofasciocutaneous flap, the radial forearm flap, the latissimus dorsi muscle system flap, the scapular and parascapular flaps, and free omentum have been used for skull base surgery. ${ }^{94-98}$ The DIEP and ALT perforator flaps are now being used for this purpose. ${ }^{57}$ The TAP flap can be used where less bulk is required but involves changing the patient's position. ${ }^{56}$ The tumors involved are complex, and the lengthy resection required allows adequate time for perforator flap dissection by a second team. Compared with myocutaneous flaps, the contour of perforator flaps is maintained as there is no muscle atrophy. The same flap can serve many purposes including; the separation of intracranial and extracranial cavities, providing a dural seal, obliteration of dead space and cover of exposed vessels. ${ }^{98}$ Furthermore, postoperative radiotherapy and chemotherapeutic agents can be delivered to the resected area without deleterious effects to the anastomosed vessels. ${ }^{99,100}$

\section{Neck Augmentation after Tumor Excision and Radical Neck Dissection}

Resection of floor of mouth tumors and radical neck dissections often leave a significant contour defect in the submandibular region and in the neck. These contour defects are often neglected when it comes to free flap reconstruction. At the same time as reconstructing the primary intraoral defect, a larger skin paddle of an ALT flap may be used, part of which is de-epithelialized; this portion is then laid into the submandibular area and even down into the neck to augment the soft tissue defect after resection. In a similar manner, muscle may be used for soft tissue augmentation, in which case a myocutaneous ALT flap is required. In this situation, raising the flap as a chimeric flap with the muscle component supplied by a separate perforator to the skin paddle allows more freedom during the inset. This versatility afforded by the free ALT flap therefore allows greater aesthetic 
refinements to be made simultaneously with reconstruction of the primary tumor site.

\section{DISCUSSION}

The advantages of using perforator flaps in head and neck reconstruction have been highlighted at length in this article. With adequate training and microsurgical skill, these flaps can be raised by a second team of surgeons at the same time as the primary surgical resection. The beauty of perforator flaps lies in the ability of the surgeon to raise flaps from almost any part of the body based on the presence of suitable perforating vessels as located by a Doppler ultrasound probe. This provides a choice of donor sites limited only by the skill of the surgeon.

Of all the perforator flaps discussed here, the ALT flap remains the most versatile and the most reliable. A previous series of 672 ALT flaps demonstrated a total flap failure rate of $1.79 \%$ and a partial flap failure rate of $2.53 \%{ }^{24} \mathrm{~A}$ meticulous technique with respect to the method of perforator dissection ${ }^{101}$ and careful inset to avoid twisting and kinking of the perforating vessels ensure flap survival. In this series, ${ }^{24}$ the majority of flaps were used for head and neck reconstruction, and the low failure rate demonstrates the reliability of this flap.

Although the ALT flap may be adapted to most indications for soft tissue reconstruction in the head and neck region, its versatility may be limited in a minority of patients who are particularly obese or hirsute. In the obese patient, excessive thinning of the flap may cause marginal necrosis, and direct closure of the donor site, even when the flap width is narrow, may be impeded, thus requiring a skin graft. Also, an excessively hairy thigh needs to be considered when the flap is being used for intraoral reconstruction, and an alternative donor site in this situation may be necessary.

A unique attribute of the ALT flap is the design of multiple flaps with variable composition. This can encompass all forms of compound flaps, including composite flaps (e.g., musculocutaneous, fasciocutaneous), chimeric flaps of which more than 100 possible combinations have been calculated from this one donor site by Hallock, ${ }^{102}$ and flow-through flaps for sequential or chain-linked flaps. Although flaps based on the subscapular axis have similar attributes, the ALT flap donor site is superior for head and neck reconstruction as the patient is maintained in the supine position to allow a two-team approach.

In patients for whom the ALT flap is not suitable, it is useful to have other perforator flaps as an alternative option. The DIEP and sGAP flaps have been popularized by surgeons reconstructing the breast. The anatomy of these flaps is well known, and they have large skin paddles of pale skin often suited to head and neck surgery. The DIEP flap is particularly useful where soft tissue bulk is crucial, and it is becoming popular in the reconstruction of tongue, floor of mouth, and cheek defects. It can be raised at the same time as tumor ablation without the need to reposition the patient. The sGAP flap can be harvested (albeit with a shorter pedicle) with the patient in the spinal position, and the flap can be raised without a change in the patient's position. The AMT flap is based on a similar arterial supply to the ALT flap, producing a similar size of tissue; this flap makes a good alternative where the ALT flap is not available.

The PAP flap has been used in a short series for head and neck reconstruction. The perforators are easily mapped preoperatively by Doppler. The main advantage over the ALT flap for intraoral reconstruction is that the PAP flap is thin and pliable. Flap debulking is not required, and thus there is no risk to the flap from radical thinning. Like the ALT flap, a sensate flap can be created if the lateral sural nerve is included in the flap. The PAP flap has low doner site morbidity and avoids the sacrifice of a main artery in the lower limb. The short pedicle can be a disadvantage when anastomosing to the small-caliber vessels found in the head and neck, particularly after neck dissection.

\section{CONCLUSION}

There have been significant advances in perforator flap surgery over recent decades. The ALT flap seems to be revolutionizing head and neck reconstruction. These flaps have been shown to be reliable, offering versatility in design and composition, as well as improved donor site morbidity when compared with other soft tissue free flaps. These flaps can often be raised using a two-team approach, without change of the patient's position, thereby reducing operative times. They can be harvested as thin, pliable, and innervated flaps for intraoral reconstruction in one patient or modified with muscle incorporated to reconstruct a massive perioral defect in another patient. The perforator flap, in particular the ALT flap with its diversity, can replace most of the other commonly used soft tissue free flaps in head and neck reconstruction.

\section{REFERENCES}

1. Ariyan S. The pectoralis major myocutaneous flap. A versatile flap for reconstruction in the head and neck. Plast Reconstr Surg 1979;63:73-81

2. Bakamjian VY. A two-stage method for pharyngoesophageal reconstruction with a primary pectoral skin flap. Plast Reconstr Surg 1965;36:173-184

3. Owens N. A compound neck pedicle designed for the repair of massive facial defects: formation, development and application. Plast Reconstr Surg 1955;15:369-389 
4. Seidenberg B, Rosenak SS, Hurwitt ES, Som ML. Immediate reconstruction of the cervical esophagus by a revascularized isolated jejunal segment. Ann Surg 1959;149: 162-171

5. Soutar DS, Scheker LR, Tanner NS, McGregor IA. The radial forearm flap: a versatile method for intra-oral reconstruction. Br J Plast Surg 1983;36:1-8

6. Hidalgo DA. Fibula free flap: a new method of mandible reconstruction. Plast Reconstr Surg 1989;84:71-79

7. Taylor GI. The angiosomes of the body and their supply to perforator flaps. Clin Plast Surg 2003;30:331-342, v v

8. Kroll SS, Reece GP, Miller MJ, et al. Comparison of cost for DIEP and free TRAM flap breast reconstructions. Plast Reconstr Surg 2001;107:1413-1416; discussion 1417-1418

9. Gedebou TM, Wei FC, Lin CH. Clinical experience of 1284 free anterolateral thigh flaps. Handchir Mikrochir Plast Chir 2002;34:239-244

10. Allen RJ, Treece P. Deep inferior epigastric perforator flap for breast reconstruction. Ann Plast Surg 1994;32:32-38

11. Koshima I, Moriguchi T, Soeda S, Kawata S, Ohta S, Ikeda A. The gluteal perforator-based flap for repair of sacral pressure sores. Plast Reconstr Surg 1993;91:678-683

12. Angrigiani C, Grilli D, Siebert J. Latissimus dorsi musculocutaneous flap without muscle. Plast Reconstr Surg 1995;96:1608-1614

13. Wei FC, Jain V, Suominen S, Chen HC. Confusion among perforator flaps: what is a true perforator flap? Plast Reconstr Surg 2001;107:874-876

14. Blondeel PN, Beyens G, Verhaeghe R, et al. Doppler flowmetry in the planning of perforator flaps. Br J Plast Surg 1998;51:202-209

15. Taylor GI, Caddy CM, Watterson PA, Crock JG. The venous territories (venosomes) of the human body: experimental study and clinical implications. Plast Reconstr Surg 1990;86:185-213

16. Mardini S, Tsai FC, Wei FC. The thigh as a model for free style free flaps. Clin Plast Surg 2003;30:473-480

17. Song R, Yang P, Liu J. Reconstruction of the cheek and lips. Clin Plast Surg 1982;9:71-72

18. Timmons MJ, Poole MD. Reconstructive surgery in the treatment of intraoral cancer. Br J Oral Maxillofac Surg $1986 ; 24: 77-85$

19. Blondeel N, Vanderstraeten GG, Monstrey SJ, et al. The donor site morbidity of free DIEP flaps and free TRAM flaps for breast reconstruction. Br J Plast Surg 1997;50:322-330

20. Song YG, Chen GZ, Song YL. The free thigh flap: a new free flap concept based on the septocutaneous artery. Br J Plast Surg 1984;37:149-159

21. Xu DC, Zhong SZ, Kong JM, et al. Applied anatomy of the anterolateral femoral flap. Plast Reconstr Surg 1988;82: 305-310

22. Kimata Y, Uchiyama K, Ebihara S, Nakatsuka T, Harii K. Anatomic variations and technical problems of the anterolateral thigh flap: a report of 74 cases. Plast Reconstr Surg 1998;102:1517-1523

23. Ao M, Uno K, Maeta M, Nakagawa F, Saito R, Nagase Y. De-epithelialised anterior (anterolateral and anteromedial) thigh flaps for dead space filling and contour correction in head and neck reconstruction. Br J Plast Surg 1999;52:261267

24. Wei FC, Jain V, Celik N, Chen HC, Chuang DC, Lin CH. Have we found an ideal soft-tissue flap? An experience with
672 anterolateral thigh flaps. Plast Reconstr Surg 2002;109: 2219-2226; discussion 2227-2230

25. Koshima I, Hosoda S, Inagawa K, Urushibara K, Moriguchi T. Free combined anterolateral thigh flap and vascularized fibula for wide, through-and-through oromandibular defects. J Reconstr Microsurg 1998;14:529-534

26. Koshima I. Free anterolateral thigh flap for reconstruction of head and neck defects following cancer ablation. Plast Reconstr Surg 2000;105:2358-2360

27. Kimata Y, Uchiyama K, Ebihara S, et al. Versatility of the free anterolateral thigh flap for reconstruction of head and neck defects. Arch Otolaryngol Head Neck Surg 1997;123: 1325-1331

28. Demirkan F, Chen HC, Wei FC, et al. The versatile anterolateral thigh flap: a musculocutaneous flap in disguise in head and neck reconstruction. Br J Plast Surg 2000;53: 30-36

29. Shieh SJ, Chiu HY, Yu JC, Pan SC, Tsai ST, Shen CL. Free anterolateral thigh flap for reconstruction of head and neck defects following cancer ablation. Plast Reconstr Surg 2000;105:2349-2357; discussion 2358-2360

30. Nakayama B, Hyodo I, Hasegawa Y, et al. Role of the anterolateral thigh flap in head and neck reconstruction: advantages of moderate skin and subcutaneous thickness. J Reconstr Microsurg 2002;18:141-146

31. Cipriani R, Contedini F, Caliceti U, Cavina C. Threedimensional reconstruction of the oral cavity using the free anterolateral thigh flap. Plast Reconstr Surg 2002;109:53-57

32. Huang WC, Chen HC, Jain V, et al. Reconstruction of through-and-through cheek defects involving the oral commissure, using chimeric flaps from the thigh lateral femoral circumflex system. Plast Reconstr Surg 2002;109: 433-441; discussion 442-443

33. Wolff KD, Grundmann A. The free vastus lateralis flap: an anatomic study with case reports. Plast Reconstr Surg 1992; 89:469-475; discussion 476-477

34. Koshima I, Fukuda H, Soeda S. Free combined anterolateral thigh flap and vascularized iliac bone graft with double vascular pedicle. J Reconstr Microsurg 1989;5:55-61

35. Koshima I, Hosoda M, Moriguchi T, Hamanaka T, Kawata S, Hata T. A combined anterolateral thigh flap, anteromedial thigh flap, and vascularized iliac bone graft for a full-thickness defect of the mental region. Ann Plast Surg 1993;31:175-180

36. Kimata Y, Uchiyama K, Ebihara S, et al. Anterolateral thigh flap donor-site complications and morbidity. Plast Reconstr Surg 2000;106:584-589

37. Kuo YR, Jeng SF, Kuo MH, et al. Free anterolateral thigh flap for extremity reconstruction: clinical experience and functional assessment of donor site. Plast Reconstr Surg 2001;107:1766-1771

38. Koshima I, Yamamoto H, Hosoda M, Moriguchi T, Orita Y, Nagayama H. Free combined composite flaps using the lateral circumflex femoral system for repair of massive defects of the head and neck regions: an introduction to the chimeric flap principle. Plast Reconstr Surg 1993;92:411-420

39. Schoeller T, Huemer GM, Shafighi M, Gurunluoglu R, Wechselberger G, Piza-Katzer H. Free anteromedial thigh flap: clinical application and review of literature. Microsurgery 2004;24:43-48

40. Koshima I, Soeda S, Yamasaki M, Kyou J. The free or pedicled anteromedial thigh flap. Ann Plast Surg 1988;21: 480-485 
41. Ao M, Nagase Y, Mae O, Namba Y. Reconstruction of posttraumatic defects of the foot by flow-through anterolateral or anteromedial thigh flaps with preservation of posterior tibial vessels. Ann Plast Surg 1997;38:598-603

42. Schoeller T, Shafighi M, Huemer GM, Wechselberger G, Piza-Katzer H. Coverage of pressure sores with free flaps. Chirurgie 2003;74:671-676

43. Koshima I, Hosoda M, Inagawa K, Moriguchi T, Orita Y. Free medial thigh perforator-based flaps: new definition of the pedicle vessels and versatile application. Ann Plast Surg 1996;37:507-515

44. Blondeel PN. One hundred free DIEP flap breast reconstructions: a personal experience. Br J Plast Surg 1999;52: 104-111

45. Hamdi M, Weiler-Mithoff EM, Webster MH. Deep inferior epigastric perforator flap in breast reconstruction: experience with the first 50 flaps. Plast Reconstr Surg 1999; 103:86-95

46. Koshima I, Soeda S. Inferior epigastric artery skin flaps without rectus abdominis muscle. Br J Plast Surg 1989;42: 645-648

47. Futter CM, Webster MH, Hagen S, Mitchell SL. A retrospective comparison of abdominal muscle strength following breast reconstruction with a free TRAM or DIEP flap. Br J Plast Surg 2000;53:578-583

48. Beausang ES, McKay D, Brown DH, et al. Deep inferior epigastric artery perforator flaps in head and neck reconstruction. Ann Plast Surg 2003;51:561-563

49. Koshima I, Nanba Y, Tsutsui T, Takahashi Y, Watanabe A, Ishii R. Free perforator flap for the treatment of defects after resection of huge arteriovenous malformations in the head and neck regions. Ann Plast Surg 2003;51: 194-199

50. Fujino T, Harasina T, Aoyagi F. Reconstruction for aplasia of the breast and pectoral region by microvascular transfer of a free flap from the buttock. Plast Reconstr Surg 1975;56: 178-181

51. Verpaele AM, Blondeel PN, Van Landuyt K, et al. The superior gluteal artery perforator flap: an additional tool in the treatment of sacral pressure sores. Br J Plast Surg 1999; 52:385-391

52. Allen RJ, Tucker C Jr. Superior gluteal artery perforator free flap for breast reconstruction. Plast Reconstr Surg 1995;95: 1207-1212

53. Blondeel PN. The sensate free superior gluteal artery perforator (S-GAP) flap: a valuable alternative in autologous breast reconstruction. Br J Plast Surg 1999;52: 185-193

54. Spinelli HM, Fink JA, Muzaffar AR. The latissimus dorsi perforator-based fasciocutaneous flap. Ann Plast Surg 1996; 37:500-506

55. Kim JT, Koo BS, Kim SK. The thin latissimus dorsi perforator-based free flap for resurfacing. Plast Reconstr Surg 2001;107:374-382

56. Guerra AB, Metzinger SE, Lund KM, Cooper MM, Allen RJ, Dupin CL. The thoracodorsal artery perforator flap: clinical experience and anatomic study with emphasis on harvest techniques. Plast Reconstr Surg 2004;114:32-41; discussion 42-43

57. Marchetti C, Gessaroli M, Cipriani R, Contedini F, Frattarelli M, Staffa G. Use of "perforator flaps" in skull base reconstruction after tumor resection. Plast Reconstr Surg 2002;110:1303-1309
58. Schwabegger A, Ninković M, Brenner E, Anderl H. Seroma as a common donor site morbidity after harvesting the latissimus dorsi flap: observations on cause and prevention. Ann Plast Surg 1997;38:594-597

59. Titley OG, Spyrou GE, Fatah MF. Preventing seroma in the latissimus dorsi flap donor site. Br J Plast Surg 1997;50: 106-108

60. Germann G, Bickert B, Steinau HU, Wagner H, Sauerbier M. Versatility and reliability of combined flaps of the subscapular system. Plast Reconstr Surg 1999;103: 1386-1399

61. Van Landuyt K, Hamdi M, Blondeel P, Monstrey S. The compound thoracodorsal perforator flap in the treatment of combined soft-tissue defects of sole and dorsum of the foot. Br J Plast Surg 2005;58:371-378

62. Yoshimura M, Imura S, Shimamura K, Yamauchi S, Nomura S. Peroneal flap for reconstruction in the extremity: preliminary report. Plast Reconstr Surg 1984;74:402-409

63. Tsai FC, Yang JY, Chuang SS, Chang SY, Huang WC. Combined method of free lateral leg perforator flap with cervicoplasty for reconstruction of anterior cervical scar contractures: a new flap. J Reconstr Microsurg 2002;18: 185-190

64. Wolff KD, Hölzle F, Nolte D. Perforator flaps from the lateral lower leg for intraoral reconstruction. Plast Reconstr Surg 2004;113:107-113

65. Pontén B. The fasciocutaneous flap: its use in soft tissue defects of the lower leg. Br J Plast Surg 1981;34:215-220

66. Carriquiry C, Aparecida Costa M, Vasconez LO. An anatomic study of the septocutaneous vessels of the leg. Plast Reconstr Surg 1985;76:354-363

67. Wolff KD, Stellmach R. The osteoseptocutaneous or purely septocutaneous peroneal flap with a supramalleolar skin paddle. Int J Oral Maxillofac Surg 1995;24(1 Pt 1): 38-43

68. Schusterman MA, Reece GP, Miller MJ, Harris S. The osteocutaneous free fibula flap: is the skin paddle reliable? Plast Reconstr Surg 1992;90:787-793; discussion 794798

69. Martin D, Pascal JF, Baudet J, et al. The submental island flap: a new donor site. Anatomy and clinical applications as a free or pedicled flap. Plast Reconstr Surg 1993;92: 867-873

70. Faltaous AA, Yetman RJ. The submental artery flap: an anatomic study. Plast Reconstr Surg 1996;97:56-60; discussion $61-62$

71. Sterne GD, Januszkiewicz JS, Hall PN, Bardsley AF. The submental island flap. Br J Plast Surg 1996;49:85-89

72. Kim JT, Kim SK, Koshima I, Moriguchi T. An anatomic study and clinical applications of the reversed submental perforator-based island flap. Plast Reconstr Surg 2002;109: 2204-2210

73. Taylor GI, Townsend P, Corlett R. Superiority of the deep circumflex iliac vessels as the supply for free groin flaps. Clinical work. Plast Reconstr Surg 1979;64:745-759

74. Hartrampf CR Jr, Noel RT, Drazan L, Elliott FL, Bennett GK, Beegle PH. Ruben's fat pad for breast reconstruction: a peri-iliac soft-tissue free flap. Plast Reconstr Surg 1994;93: 402-407

75. Safak T, Klebuc MJ, Mavili E, Shenaq SM. A new design of the iliac crest microsurgical free flap without including the "obligatory" muscle cuff. Plast Reconstr Surg 1997;100: 1703-1709 
76. Kimata Y, Uchiyama K, Sakuraba M, et al. Deep circumflex iliac perforator flap with iliac crest for mandibular reconstruction. Br J Plast Surg 2001;54:487-490

77. Kimata Y. Deep circumflex iliac perforator flap. Clin Plast Surg 2003;30:433-438

78. Urken ML, Biller HF. A new bilobed design for the sensate radial forearm flap to preserve tongue mobility following significant glossectomy. Arch Otolaryngol Head Neck Surg 1994;120:26-31

79. Urken ML, Moscoso JF, Lawson W, Biller HF. A systematic approach to functional reconstruction of the oral cavity following partial and total glossectomy. Arch Otolaryngol Head Neck Surg 1994;120:589-601

80. Lyos AT, Evans GR, Perez D, Schusterman MA. Tongue reconstruction: outcomes with the rectus abdominis flap. Plast Reconstr Surg 1999;103:442-447; discussion 448-449

81. Beasley NJ, Gilbert RW, Gullane PJ, Brown DH, Irish JC, Neligan PC. Scalp and forehead reconstruction using free revascularized tissue transfer. Arch Facial Plast Surg 2004; 6:16-20

82. Borah GL, Hidalgo DA, Wey PD. Reconstruction of extensive scalp defects with rectus free flaps. Ann Plast Surg 1995;34:281-285; discussion 285-287

83. Ylä-Kotola TM, Kauhanen MS, Koskinen SK, AskoSeljavaara SL. Magnetic resonance imaging of microneurovascular free muscle flaps in facial reanimation. Br J Plast Surg 2005;58:22-27

84. Lutz BS. Aesthetic and functional advantages of the anterolateral thigh flap in reconstruction of tumor-related scalp defects. Microsurgery 2002;22:258-264

85. Yang JY, Tsai FC, Chana JS, Chuang SS, Chang SY, Huang WC. Use of free thin anterolateral thigh flaps combined with cervicoplasty for reconstruction of postburn anterior cervical contractures. Plast Reconstr Surg 2002;110:39-46

86. Urken ML, Weinberg H, Vickery C, Buchbinder D, Lawson $\mathrm{W}$, Biller HF. Oromandibular reconstruction using microvascular composite free flaps. Report of 71 cases and a new classification scheme for bony, soft-tissue, and neurologic defects. Arch Otolaryngol Head Neck Surg 1991;117: 733-744

87. Wei FC, Celik N, Chen HC, Cheng MH, Huang WC. Combined anterolateral thigh flap and vascularized fibula osteoseptocutaneous flap in reconstruction of extensive composite mandibular defects. Plast Reconstr Surg 2002; 109:45-52

88. Wei FC, Demirkan F, Chen HC, Chen IH. Double free flaps in reconstruction of extensive composite mandibular defects in head and neck cancer. Plast Reconstr Surg 1999; 103:39-47
89. Sanger JR, Matloub HS, Yousif NJ. Sequential connection of flaps: a logical approach to customized mandibular reconstruction. Am J Surg 1990;160:402-404

90. Hallock GG. Simultaneous transposition of anterior thigh muscle and fascia flaps: an introduction to the chimera flap principle. Ann Plast Surg 1991;27:126-131

91. Cordeiro PG, Santamaria E. A classification system and algorithm for reconstruction of maxillectomy and midfacial defects. Plast Reconstr Surg 2000;105:2331-2346; discussion 2347-2348

92. Cordeiro PG, Disa JJ. Challenges in midface reconstruction. Semin Surg Oncol 2000;19:218-225

93. Chana JS, Chen HC, Sharma R, Hao SP, Tsai FC. Use of the free vastus lateralis flap in skull base reconstruction. Plast Reconstr Surg 2003;111:568-574; discussion 575

94. Urken ML, Catalano PJ, Sen C, Post K, Futran N, Biller HF. Free tissue transfer for skull base reconstruction analysis of complications and a classification scheme for defining skull base defects. Arch Otolaryngol Head Neck Surg 1993;119: 1318-1325

95. Clayman GL, DeMonte F, Jaffe DM, et al. Outcome and complications of extended cranial-base resection requiring microvascular free-tissue transfer. Arch Otolaryngol Head Neck Surg 1995;121:1253-1257

96. Schliephake H, Schmelzeisen R, Samii M, Sollmann WP Microvascular reconstruction of the skull base: indications and procedures. J Oral Maxillofac Surg 1999;57:233-239

97. Neligan PC, Mulholland S, Irish J, et al. Flap selection in cranial base reconstruction. Plast Reconstr Surg 1996;98: 1159-1166; discussion 1167-1168

98. Fisher J, Jackson IT. Microvascular surgery as an adjunct to craniomaxillofacial reconstruction. Br J Plast Surg 1989;42: 146-154

99. Mulholland S, Boyd JB, McCabe S, et al. Recipient vessels in head and neck microsurgery: radiation effect and vessel access. Plast Reconstr Surg 1993;92:628-632

100. Arinci A, Topalan M, Aydin I, et al. Effects of early preand postoperative irradiation on the healing of microvascular anastomoses. J Reconstr Microsurg 2000;16:573-576

101. Celik N, Wei FC, Lin CH, et al. Technique and strategy in anterolateral thigh perforator flap surgery, based on an analysis of 15 complete and partial failures in 439 cases. Plast Reconstr Surg 2002;109:2211-2216; discussion 2217-2218

102. Hallock GG. Discussion. Have we found an ideal soft-tissue flap? An experience with 672 anterolateral thigh flaps. Plast Reconstr Surg 2002;109:2227-2230

103. Yang KC, Leung JK, Chen JS. Double-paddle peroneal tissue transfer for oromandibular reconstruction. Plast Reconstr Surg 2000;106:47-55 